\title{
Get Involved: \\ Marian (Molly) Kennedy, Committee Chair
}

\author{
Maria Guzzo
}

"Get Involved" is a recurring End Notes feature that spotlights the work of TMS volunteers and shows the wide range of activities available through TMS. This month, Marian (Molly) Kennedy, assistant professor in the Department of Materials Science and Engineering at Clemson University, discusses her volunteer experiences as chair of the TMS Mechanical Behavior of Materials Committee, which is part of the TMS Structural Materials Division.

Q. Please describe your role as a member of the Structural Materials Division (SMD) Council and as Chair of the Mechanical Behavior of Materials Committee?

A. As the chair of the Mechanical Behavior of Materials Committee, my focus is on empowering our members to organize symposia and workshops and to help identify deserving members for awards. I think chairing has to be the best volunteer position at TMS! I have been able to work with experts in my field, get their perspective on emerging topics and enable them to bring their symposia to life. I only wish that there were more awards to give to our committee members for their great work (I hope the TMS Board is reading this).

Q. As a result of your TMS volunteer experience, what leadership skills did you develop and how do they apply in your profession?

A. The members of the Mechanical Behavior of Materials Committee taught me how to run efficient, wellorganized meetings. The prior chairs (Drs. Ellen Cerreta and Brad Boyce) emphasized that every meeting needs a purpose, agenda and an end time before inviting others. As a previous member, I appreciated their adherence to these principles and I stick to them today both as a TMS committee chair and a faculty member.
Q. You began on your TMS leadership path by receiving a 2008 TMS Young Leaders Professional Development Award. How did that award encourage further TMS involvement?

A. The award enabled me to attend TMS-sponsored conferences and become an active member, and then the chair, of the TMS Mechanical Behavior of Materials Committee. It was a wonderful experience because TMS was the first professional society to which I was able to contribute in a technical manner. The then-committee chairs encouraged me to champion a new symposium at the TMS annual meeting. During the planning process, the other committee members gave their time to help me refine the symposium's technical focus, and the TMS staff guided me through planning and implementation. I knew volunteering was good for our field, but this experience showed me how volunteering could benefit my personal research. I was able to bring together both the established and emerging leaders to a symposium central to my research. Reading and organizing the submitted abstracts, and listening to the speakers influenced my personal research directions then, and still do.

Q. How has the experience helped you become more involved in TMS, and specifically in SMD activities?
A. As a new faculty member, it was daunting to balance research, teaching and service. I wanted to contribute as an emerging researcher to my field beyond research and papers. By becoming involved in a technical committee related directly to my research focus, I am able to contribute and maintain the focus needed for progressing through the tenure track. I really want both students and emerging professionals to know that they are wanted on every technical committee. To become involved, they can show up to a technical committee or email the committee chair or the TMS staff. You don't need an award for committee membership and the committees always need bright, energetic members.

Q. You also provide leadership as a Faculty Advisor for the Material Advantage program at Clemson. How do you see TMS assisting and benefitting our student and young professional members?

A. The Material Advantage (MA) program has provided many opportunities for our students at Clemson University, including scholarships, competitions and professional development activities. I was lucky that when I arrived at Clemson University, the MA faculty advisor position was open.

Maria Guzzo is a contributing writer for JOM. 